\title{
Correction to: Mapping a Plasmodium transmission spatial suitability index in Solomon Islands: a malaria monitoring and control tool
}

Isabelle Jeanne ${ }^{1 *}\left(\mathbb{D}\right.$, Lynda E. Chambers $^{1}$, Adna Kazazic ${ }^{1}$, Tanya L. Russell ${ }^{2}$, Albino Bobogare ${ }^{3}$, Hugo Bugoro ${ }^{4}$, Francis Otto ${ }^{3}$, George Fafale ${ }^{3}$ and Amanda Amjadali ${ }^{5}$

\section{Correction to: Malar J (2018) 17:381}

https://doi.org/10.1186/s12936-018-2521-0

Following publication of the original article [1], one of the authors flagged that the images for Figs. 2 and 3 were swapped in the published article-Fig. 2 had the image meant for Fig. 3 and vice versa.

As such, the original article [1] has been updated to correct this error.

The publisher apologizes for any inconvenience caused.

\section{Author details}

${ }^{1}$ Australian Bureau of Meteorology, Melbourne, VIC, Australia. ${ }^{2}$ Australian Institute of Tropical Health and Medicine, James Cook University, Cairns, QLD, Australia. ${ }^{3}$ Ministry of Health and Medical Services, National Vector Borne Disease Control Programme, Honiara, Solomon Islands. ${ }^{4}$ Research Department, Solomon Islands National University, Honiara, Solomon Islands. ${ }^{5}$ Pacific Science Solutions, Suva, Fiji.

The original article can be found online at https://doi.org/10.1186/s1293 6-018-2521-0

\section{Publisher's Note}

Springer Nature remains neutral with regard to jurisdictional claims in published maps and institutional affiliations.

Published online: 19 November 2018

\section{Reference}

1. Jeanne I, Chambers LE, Kazazic A, Russell TL, Bobogare A, Bugoro H, Otto F, Fafale $G$, Amjadali A. Mapping a Plasmodium transmission spatial suitability index in Solomon Islands: a malaria monitoring and control tool. Malar J. 2018;17:381. https://doi.org/10.1186/s12936-018-2521-0. 